\title{
León XIII y los terciarios franciscanos: una condena del pauperismo en los inicios del catolicismo social
}

\author{
Begoña Pérez Calle'; José Luis Malo Guillén ${ }^{2}$
}

Recibido: 07 de febrero de 2017 / Aceptado: 01 de junio de 2018

Resumen. Ya desde los inicios de la revolución industrial, el pauperismo en que derivó un alto porcentaje de las clases trabajadoras llamaría la atención de la Iglesia y generaría distintos discursos. Las vertientes fueron variadas, desde el corte caritativo al solidario, desde el intervencionista Iglesia-Estado al de pura conciencia. De una manera u otra, los debates generados se enmarcarían en una época presidida por un problema: la cuestión obrera, de la cual se estaban ocupando por otra parte las teorías socialistas que adquirían cada vez más protagonismo en la ideología de las clases trabajadoras.

En el último tercio del siglo XIX, el Papa León XIII hizo una puesta de largo de esa preocupación vaticana por el estado de pobreza en que la industrialización había dejado a amplios sectores de la población. Este artículo identifica el fondo de esa cuestión con una deriva del pensamiento franciscano que nunca abandonó al sacerdote y miembro de la Orden Tercera Gioacchino Pecci.

Palabras clave: Catolicismo social; franciscanismo; pauperismo; cuestión obrera; mercado ético.

Clasificación JEL: B19, N43, Z12.

\section{[en] Leon XIII and the Franciscan tertiary: a condemnation of pauperism at the dawn of social Catholicism}

Abstract. From the beginning of the industrial revolution, the pauperism in which a high percentage of the working classes derived, attracted the attention of the Church and generated different discourses. We can find varied dimensions, from charitable to solidary, from the Church-State interventionist to pure conscience. In one way or another, the generated discussions were taken at a time when a main problem to solve was the Labour Question, a matter that was being addressed by the socialist theories, which began to assume an important role in the ideology of the working classes.

In the last third of $19^{\text {th }}$ century, Pope Leo XIII made a presentation of that Vatican concern for the state of poverty in which industrialization had left large sections of population. This article identifies the background of this question with a drift of Franciscan thought that never left Gioacchino Pecci, priest member of the Third Order .

Keywords: Social Catholicism; franciscanism; pauperism; worker question; ethic market.

Classification JEL: B19, N43, Z12.

Sumario: 1. Introducción. 2. Un hombre y una época: Gioacchino Pecci. El terciario franciscano que se convertiría en León XIII. 2.1. Las influencias neotomistas en el pensamiento de León XIII. 2.2. El sustrato franciscano. 2.3. Una hoja de ruta: rerum novarum. 3. Un modelo práctico de sociedad y organización económica: la orden tercera franciscana y la empresa social. 3.1. La estación de los congresos. 3.2. León Harmel y el modelo de empresa social. 4. Conclusiones. 5. Bibliografía.

\footnotetext{
Universidad de Zaragoza. Departamento de Análisis Económico.

2 Universidad de Zaragoza. Departamento de Estructura e Historia Económica y Economía Pública.
} 
Cómo citar: Pérez Calle, B.; Malo Guillén, J. L. (2018) León XIII y los terciarios franciscanos: una condena del pauperismo en los inicios del catolicismo social, en Iberian Journal of the History of Economic Thought 5(1) (2018), 45-56.

\section{Introducción}

Ante los males generados por la revolución industrial y el pauperismo existente, durante la segunda mitad del siglo XIX se intensifican los ataques al liberalismo causante y comienza la búsqueda de cómo afrontar el mal desde la raíz. De esta forma, se configura una oposición generalizada por parte de la Iglesia a las ideas políticas y económicas del liberalismo. Esto, en un breve periodo de tiempo, adquiriría forma de denuncia religiosa y moral, conformando el cuerpo de la Doctrina Social de la Iglesia, que la historia admite constituida con la publicación de la encíclica Rerum Novarum.

Los estudios sobre pensamiento económico hasta la fecha no han tenido en cuenta el sustrato franciscano existente en el pensamiento del Papa León XIII, autor de la encíclica y artífice del catolicismo social. Como afirman Trincado y Perdices (2015) la historia del pensamiento económico es doblemente compleja, al amalgamar naturalezas tan distintas como filosofía, ética, historia de la ciencia y crítica literaria, $y$ en este sentido, el tema que nos ocupa ha sido vagamente abordado, y en cualquier caso siempre desde perspectivas históricas o teológicas por parte de investigadores pertenecientes al mundo franciscano, lo que lleva a precisar de un estudio transversal e interdisciplinar.

En efecto, al igual que combatir el pauperismo medieval fue un reto para la familia franciscana del siglo XIII, ocuparse de la cuestión obrera como si fuese una versión de ese pauperismo, viajando quinientos años en el tiempo, $\mathrm{y}$ de las nuevas situaciones de pobreza generadas a causa de la revolución industrial, fue su reto a finales del siglo XIX ${ }^{3}$. Así, dicha familia, llamada a volver a sus inicios para luchar contra el pauperismo desde diversos frentes, sentiría el despertar de una nueva conciencia que identificaría a éste con la cuestión social, ampliaría la perspectiva de caridad a otra diferente basada en las relaciones capital-trabajo, afrontadas desde una base de justicia social, y daría un paso al modificar el concepto hacia el de caridad mutua, una forma pragmática de extensión de la virtud teologal, más cercano al de solidaridad. A partir de la visión de la Orden Tercera de San Francisco, alentada e impulsada por León XIII surgirían una serie de posiciones que, en sus variadas manifestaciones, conformarían algunos de los elementos básicos de un pensamiento que condenó al pauperismo en la teoría y en la práctica.

Puede afirmarse que la Iglesia se encontraba ciertamente rezagada en la época ya que el pensamiento católico mostraba una debilidad sustancial para responder a las problemáticas generadas, viniendo suplantado por formas de saber que podían sustituir perfectamente a la religión. Cierto que el liberalismo había sido atacado por Gregorio XVI en las encíclicas Mirari Vos de 1832 y Singulari Nos de 1834, y que los efectos perversos del capitalismo sobre la pobreza se venían analizando y denunciando puntualmente, especialmente en Francia y Alemania. En este sentido, y a pesar de que no es la intención de este trabajo extenderse en explicar líneas puntuales precursoras, no pueden dejar de comentarse ejemplos puntuales tan significativos como la iniciativa hacia una Economía Política Cristiana de Alban de Villeneuve-Bargemont, quien en 1834 publicaría una obra dedicada, entre otros temas, a estudiar el pauperismo en una línea reformadora, y con un título muy significativo: Économie politique chrétienne, ou Recherches sur la nature et les causes du pauperisme en France et en Europe, et sur les moyens de le soulager et de le prevenir. El mismo autor publicaría en 1841 un manual sobre la Historia de la Economía Política en la misma línea: Histoire de l'Économie Politique 4 .

Sin embargo hay que apuntar que las interesantes iniciativas previas, en las décadas de 1830 y 1840 , no contaban con un elemento estímulo que vendría después y podemos nombrar la gran amalgama entre conciencia cristiana verdadera y temor a la pérdida de las clases

Para un estudio amplio comparado de las primeras fraternidades franciscanas medievales frente a su situación en el siglo XIX véase Lombardi (1980).

4 Sobre la obra y significatividad de Alban de Villeneuve Bargemont véase el exhaustivo estudio de Tiano (1993). 
trabajadoras: el Manifiesto Comunista de Marx y Engels, que poco a poco durante la segunda mitad del siglo XIX, se iría traduciendo y extendiendo entre los sectores proletarios de la población.

Paralelamente las jerarquías e intelectuales eclesiásticos adquirirían conciencia de la problemática social en que había degenerado la revolución industrial así como de la iniciativa y lenta pero profunda popularidad del Manifiesto. Centrando la preocupación motor en la cuestión obrera y la pobreza, la Iglesia precisaba además de aportar una vía a las soluciones propuestas por el socialismo que tanto estaba extendiéndose entre los sectores proletarios. De esta forma, a partir de la década de 1850, comenzarían los discursos dedicados a la búsqueda de una solución a la llamada cuestión obrera, por parte de hombres de iglesia, que a la vez condenaban lo que entendían como el "error" de las soluciones colectivistas de Marx y Engels. En este sentido fueron destacadas las posturas por parte de clérigos, algunos ostentando altos puestos de la jerarquía eclesiástica como fueron los cardenales Von Ketteler, Marmillod (ambos además terciarios franciscanos), Manning y Gibbons, otros desde su labor pastoral como sacerdotes diocesanos, destacando Adolf Kolping, o también laicos como Frédéric Ozanam y Léon Harmel, terciarios franciscanos también. En un principio, el problema venía afrontado con un enfoque contrarrevolucionario, no proclive a la igualdad democrática y sobre todo lleno de indicaciones pastorales, en una línea reformista interna a la Iglesia que añadía también la preocupación por perder el espacio que el socialismo podía "arrebatarle". Durante el pontificado de Pio IX tendrían lugar nuevos ataques al liberalismo en la encíclica Quanta Cura de 1864.

Es importante destacar de nuevo aquí a Wilhelm Emmanuel Von Ketteler, quien priorizó la cuestión obrera como el principal problema de la cuestión social de su tiempo en su obra de 1864 Die Arbeiterfrage und das Christentum, revelándose en su pensamiento cierta cercanía a las demandas trabajadoras de Ferdinand Lasalle ${ }^{5}$.

\section{Un hombre y una época: Gioacchino Pecci. El terciario franciscano que se convertiría en León XIII.}

Se ha admitido una perspectiva general de León XIII como un Papa moderno, como apunta Montero (1983), que aportaría grandes novedades críticas a la cuestión social durante su pontificado. Las investigaciones hasta la fecha vienen, mayoritariamente, concentrándose en el componente neotomista de su pensamiento, pero apenas han apuntado a la figura del León XIII prepapal, a su filosofía franciscana y su relación con los franciscanos terciarios, su entusiasmo con el modelo de empresa social como solución a la cuestión obrera y el equilibrio capital-trabajo, todo ello fundamental para entender la trayectoria del catolicismo social durante su pontificado, que discurrió entre 1878 y 1903.

Vicenzo Gioacchino Rafaelle Luigi Pecci nació en Carpineto Romano (Roma) en 1810 y se formó con los jesuitas de Viterbo. Procedía de una familia perteneciente a la pequeña nobleza romana pero de costumbres austeras, perteneciendo su madre a la Orden Tercera de San Francisco ${ }^{6}$, orden en la que él acabaría ingresando en 1872, después de haber sido obispo y cardenal. Ya desde niño, Gioacchino Pecci había cultivado la amistad con frailes de la Orden Primera.

Desde 1824 realizaría los estudios de Filosofía y Teología en el Collegio Romano y posteriormente los de Derecho Civil y Canónico en la Università della Sapienza, ampliando su formación en Administración y asuntos diplomáticos en la Accademia dei Nobili Ecclesiastici en 1832. Ordenado sacerdote en 1837, fue delegado del Estado Pontificio para Benevento un año después y desde 1841 desarrollaría la misma labor en Spoleto y Perugia. En 1843 fue nombrado arzobispo titular de Damietta y tres meses después nuncio apostólico en Bélgica, uno de los países donde se congregaban los principales reformadores europeos de la época y en el que tuvo la oportunidad de contemplar de cerca la Europa industrial e imbuirse de sus problemas. A ello se añaden algunas estancias

Sobre la proximidad de von Ketteler con dichas demandas de Lasalle véase Eissrich (2017).

La Orden Franciscana Seglar, como se conoce también a la Orden Tercera de San Francisco, según viene indicado en su Regla (cap. 1. Art. 2) "se configura como una unión orgánica de todas las fraternidades católicas, esparcidas por el mundo entero y abiertas a todo grupo de fieles, en las cuales los hermanos y las hermanas, impulsados por el Espíritu a alcanzar la perfección de la caridad en su estado seglar, se comprometen con la Profesión a vivir el Evangelio a la manera de Sn Francisco...” (OFS, 2001: 23). 
en Renania (donde observaría de cerca el trabajo social desarrollado por el arzobispo Von Geisel), así como otras en Londres y París. Regresa a Italia en 1846, siendo nombrado obispo de Perugia, si bien bajo observación, dadas las quejas del rey belga Leopoldo I sobre la gestión de Pecci en Bruselas ${ }^{7}$.

$\mathrm{Su}$ estancia belga le permitió convivir con una sociedad en la cual clérigos y laicos protagonizarían diversas iniciativas sociales del momento. Esta realidad ha llevado a que algunos autores sitúen aquí el inicio de sus intereses por la cuestión operaria, a lo que hay que apuntar que desde hace algunos años se pone en tela de juicio esta hipótesis atendiendo a los orígenes familiares franciscanos de Pecci (Malgeri, 2000: 577).

En Perugia permanecería 31 años, en los que su labor fue absolutamente transversal, discurriendo por los caminos de la instrucción y la formación, de la obra social y de la pastoral. A nivel formativo destaca la fundación de la Accademia di San Tommasso; en cuanto a la dirección pastoral hay que señalar la organización de numerosas misiones, así como la construcción de iglesias en localidades que aún no contaban con ellas. Pero lo más importante cara al tema que nos ocupa es lo que puede considerarse su principal gran empeño y que marca un punto de inflexión en la labor episcopal en Perugia: el empuje a sus diocesanos en cuanto a implicarse en aliviar las necesidades de un gran número de conciudadanos que habían caído en la miseria. Es aquí donde Pecci destinaría grandes esfuerzos y dedicaría sus competencias en administración y gestión, tanto en herramientas de previsión, caso de la fundación de los Monti Frumentari ${ }^{8}$ y las cajas de ahorro, como en otras de salud pública, dentro de lo que destacan las campañas de vacunación contra la viruela.

Evidentemente, cuando Gioacchino Pecci fue nombrado Papa en 1878 contaba con una larga trayectoria gestora y social a sus espaldas, lo que venía unido a la formación e influencias que había recibido. Teniendo en cuenta esto, una línea importante y de gran utilidad en cuanto al estudio que nos ocupa es el pensamiento económico del hombre y el sacerdote que llegaría al Papado, hemos de comenzar por distinguir dos influencias básicas, forjadas a consecuencia de su trayectoria vital: el neotomismo y el franciscanismo.

\subsection{Las influencias neotomistas en el pensa- miento de León XIII}

Viene aceptándose como un elemento básico en la génesis del catolicismo social la reflexión sobre la sociedad y la economía derivada a su vez de la proyección social del netomomismo o neoescolástica, corriente reivindicativa del pensamiento de Santo Tomás de Aquino y cuyo objetivo era la resolución de problemas contemporáneos ${ }^{9}$.

Gioacchino Pecci estudió y conoció a fondo la filosofía de Santo Tomás. A causa de ello se ha apuntado frecuentemente a su perfil neotomista, incluso asociando el propio neotomismo como un pistoletazo de salida para su encíclica Aeterni Patris. Verdaderamente, no puede negarse que el joven Pecci, además de estudiarlo, hubiese comenzado a apreciar el tomismo durante su época de estudiante en el Collegio Romano, entre 1825 y 1828, en la época durante la cual Luigi Taparelli ${ }^{10}$ fue rector. Como hemos comentado, cuando ya fue arzobispo de Perugia fundó en 1872 la Accademia di San Tommasso junto a su hermano Giuseppe Pecci. Además, desde que fue elegido Papa en 1878, se rodeó de los tomistas más destacados. En 1880 fundaría en Roma la Pontificia Accademia di San Tommaso, de la que serían presidentes dos cardenales, su hermano Giuseppe y Tommaso Zigliara, y en cuya tarea científica colaborarían dos españoles de perfil

Para más información véase Rivi y Gasparini (2012).

Complementarios a los Montes de Piedad, los Monti Frumentari operaban en las zonas rurales desde el siglo XVII. Este tipo de Monti propusieron dar acceso al crédito también a los más pobres con una tasa de interés relativamente baja, siempre otorgando sus préstamos caso por caso según las necesidades reales.

9 A principios del siglo XIX en Italia puede situarse el comienzo de la neoescolástica con los hermanos jesuitas Serafino y Domenico Sordi cuyos maestros fueron profesores de la Universidad de Cervera y jesuitas muchos de ellos, en Italia tras su expulsión en el siglo XVIII. Serafino Sordi instruyó en el tomismo a Luigi Taparelli y Giuseppe Pecci entre otros. (Pérez Calle, 2015: 986).

10 Luigi Taparelli escribió entre 1840 y 1843 su obra Saggio Teoretico di diritto naturale apoggiatto sui fatti, la cual ofrece una síntesis de lo que se conocería como neotomismo, y que apunta a cómo la Economía debía ser estudiada dentro de la comunidad políticamente unida y al servicio de toda la sociedad, siendo la obligación de la Ciencia Económica investigar cómo lograr el máximo bienestar material, atacando al liberalismo por su posición antirreligiosa y su optimismo en materia de libertad. Taparelli apuntaría como las sociedades había de organizarse según sistema de relaciones justas y naturales entre todas ellas, desde la familia hasta el Estado y más allá. Para más información véase O’Neill y Domínguez (2001). 
universitario neotomista, el fraile dominico Zeferino González ${ }^{11}$ y el profesor José Manuel Ortí y Lara ${ }^{12}$.

Pero si verdaderamente hemos de hablar de un punto de inflexión para el neotomismo, hemos de decir que esta filosofía se consagró a raíz de la encíclica de León XIII Aeterni Patris, publicada el 4 de agosto de 1879 , documento que hacía un llamamiento a la reorganización cristiana de la sociedad a la vez que a la "Restauración de la filosofía cristiana conforme a la doctrina de Santo Tomás de Aquino", afirmando que "todas las ciencias humanas deben esperar aumento y prometerse grande auxilio de esta restauración de las ciencias filosóficas por Nos propuesta" (León XIII, 1879: 12).

\subsection{El sustrato franciscano}

La filosofía franciscana presidió el pensamiento económico más profundo de Gioacchino Pecci, dando muestras continuas de ello a lo largo de su vida. Terciario franciscano él mismo, e hijo de terciaria como ya se ha comentado, León XIII puso en el franciscanismo sus mayores preferencias y sus mayores esperanzas para la regeneración de la sociedad cristia$\mathrm{na}^{13}$. Es fundamental el perfil franciscano de León XIII y la influencia de esta filosofía en Rerum Novarum, al ser considerada la encíclica que instituye el cuerpo doctrinal del catolicismo social, especialmente en lo que respecta a sus fundamentos económicos.

Consideramos de suma importancia el profundizar en esta línea de reflexión, puesto que la historia del pensamiento no se ha ocupado de ella hasta ahora. Ha de añadirse que el cuerpo principal de análisis de su pensamiento se ha venido centrando en gran manera tanto en dicha encíclica como en la Aeterni Patris, de 1879, cuando es fundamental, como apunta Della Balda (2010) realizar un recorrido, al menos simplificado, por los escritos del prolífico y longevo Papa, para entender el punto de inflexión que significó su pontificado.
En este sentido hay que comenzar por apuntar que, si bien ha sido estudiados en profundidad los componentes neotomistas de Aeterni Patris en 1879, las investigaciones hasta la fecha parecen olvidar, salvo algunas excepciones, los mensajes escritos tres años después en la encíclica Auspicato Concessum, así como el gran apoyo de Pecci a las publicaciones periódicas que difundieran los ideales franciscanos. Siendo todavía obispo de Perugia, había impulsado por todos los medios la expansión de la tercera orden en todas las parroquias de su diócesis. Nombrado Papa, comenzaría presentando un programa de cercanía al panorama cultural y sociopolítico de su tiempo desde su primera encíclica Inscrutabili Dei Consilio, de 1878; y posiblemente su empeño era presentar Aeterni Patris como la primera de una serie de intervenciones para alentar hacia una fusión filosófica y cristiana de la sociedad. Dicha fusión habría de ser organizada desde la base, a través de la iniciativa del laicado, con el fin de imbuir de espíritu evangélico todos los aspectos de la vida moderna. Esto debía producirse según el lema franciscano "pasando del evangelio a la vida y de la vida al evangelio" 14 ; es decir, se trataba de una invitación a que la sociedad se organizase según postulados de la orden tercera de San Francisco, la cual podía ser un modelo perfectamente adaptado a los avances que pudieran venir. De esta forma, durante su pontificado, la orden tercera recibiría un gran estímulo para recobrar el papel que el propio Francisco le había dado en el siglo XIII, como armonizadores sociales y luchadores contra el pauperismo. Para ello, el Papa habría de dotar de instrumental adecuado a la Tercera, pudiendo datarse un centenar de documentos de instrucción dirigidos a ella (Rivi y Gasparini, 2012: 19).

El 17 de septiembre de 1882 publicó la encíclica Auspicato Concessum, aprovechando la celebración del séptimo centenario del nacimiento de San Francisco de Asís. En esta encíclica León XIII recorrió la vida del santo umbro, profundizando en su faceta como re-

Zeferino González, dominico, Profesor de Filosofía y Teología en la Universidad de Manila, fue una de las figuras más destacadas del catolicismo social español y uno de los más importantes de los pensadores neoescolásticos del momento, fundador de los Círculos Católicos de Obreros en Córdoba una vez nombrado obispo de esa ciudad en 1875. En su obra La Defensa de la Sociedad (1877) identificó a la sociedad como la colección de muchas familias puestas en contacto, no una suma de individuos, a partir de la cual habría de configurarse el mercado.

12 Juan Manuel Ortí y Lara fue alumno de Zeferino González y uno de los profesores universitarios neotomistas más destacados.

13 Desde Pio IX (1846-1878) hasta Juan XXIII (1958-1963), todos los Papas fueron miembros de la Orden Tercera antes de su ascensión al pontificado.

14 Tal y como reza el capítulo II, artículo 4 de su Regla (OFS, 2001: 27). 
formador social que llamaba a la virtud en la época que le tocó vivir. Realizaba además un análisis de la sociedad individualista del momento según semejanza con la del siglo XIII y su reforma según el modelo de Francisco, poniendo de manifiesto que tanto en dicha época como en la que el Papa estaba escribiendo, la caridad era insuficiente para afrontar la miseria del pueblo, y ello a causa del egoísmo e individualismo en el que vivía la sociedad. Para León XIII la desigualdad existe, pero si la sociedad se corrige según la fórmula del auxilio mutuo no cabrán soluciones basadas en revoluciones y discursos del odio, pues la pobreza es un efecto perverso de una desigualdad sin soluciones cristianas. La lucha contra la condición egoísta en el cristiano con el fin de lograr mecanismos paliativos del pauperismo esboza una primera línea de lo que serían los postulados posteriores de doctrina social católica. Para reforzar dicha lucha, León XIII hacía un llamamiento a la revigorización de todas las instituciones franciscanas, en especial de la orden tercera, como el mejor antídoto contra los egoísmos que dan pretexto al socialismo. En los congresos terciarios se produciría una relectura de esta encíclica a raíz de Rerum Novarum, tratándola como texto de referencia y pauta para las reformas sociales que de ellos derivarían.

El 30 de mayo de 1883 León XIII promulgó una nueva Regla para la Orden Tercera, dentro de la Constitución apostólica Misericors Dei Filius, con el fin de adaptar a los nuevos tiempos y a las exigencias de la vida moderna la regla precedente de 1289 , de manera que fuese un instrumento de santificación abierto a todos y dedicado a la cuestión social, una alternativa diferente al socialismo que se extendía entre las clases desfavorecidas. No podía existir acción religiosa sin acción social ni acción social sin acción religiosa ${ }^{15}$. Dado este paso trascendental, el Papa no perdió ocasión en los años siguientes de interesar a todo el episcopado católico en la propagación de dicha Orden.

Otra intervención importante de impronta franciscana viene contenida en la encíclica Humanum Genus de 1884, donde señala la orden tercera como un remedio eficaz para evitar la proliferación de las sectas masónicas. En 1888 publicó Libertas Praestantissimum, un documento que consta de dos partes, la primera referida a la libertad como un don y la segunda una enérgica condena al liberalismo político, por cuanto su negación de la autoridad divina y proclamación de la soberanía de la razón, lo que se opone a la tesis cristiana según la cual la libertad racional es exclusiva de los seres racionales y es la que ha de fundar la libertad moral, siendo ésta última la que ha de proyectarse en libertad social y política. (Ruiz, 1986: 96).

\subsection{Una hoja de ruta: rerum novarum}

León XIII ha sido el pontífice más prolífico en encíclicas, con 87 publicadas y una media anual de 3,48 , además del segundo más citado, con 457 citas recibidas en Web of Science (datos de 2016), tal y como apuntan Repiso, Ahedo y Montero (2018). Este estudio revela además que la encíclica más citada es Rerum Novarum (1891).

Sobre Rerum Novarum se ha escrito y disertado ampliamente, y dato relevante es el que acabamos de apuntar. Pero hemos de hacer otro apunte en el tema que nos ocupa, y es que el Papa Pecci se encontraba a finales de 1890 en un momento propicio para enviar desde el Vaticano un mensaje clave a la cristiandad: la fórmula para una organización socioeconómica cristiana en la cual la cuestión social fuese el primer objetivo a tener en cuenta. El problema obrero precisaba de soluciones, el socialismo crecía y a pesar de que muchas iniciativas se venían llevando a cabo desde la sociedad cristiana, no se podía hablar todavía de una doctrina arraigada. Es de destacar que, con el apoyo de experiencias concretas de seglares católicos franceses, belgas y alemanes preocupados por la cuestión social, había comenzado a reunirse la denominada Unión de Friburgo entre 1885 y 1891, integrada por un conjunto de personas que habían venido trabajando en el cambio social desde la opción católica y cuyo objetivo central era buscar una alternativa al sistema de mercado liberal a través de la restauración del orden basado en el ideal católico medieval. Sus reflexiones estaban basadas en un claro anti-liberalismo y anti-industrialismo, plataformas dialécticas a partir de las que se atacaba al mercado y a la competencia que había configurado el sistema industrial (Fraile, 1998: 62). Sus propuestas para la mejora social incluirían la idea de una legislación

Así se referiría a León XIII su amigo Leon Harmel en 1899 (Bigi y Monaco, 1985: 60) 
internacional para los trabajadores, la organización corporativa para las explotaciones agrícolas y formas transversales de sindicatos (Pérez, 2015: 989).

Finalmente, el 15 de mayo León XIII publicó Rerum Novarum, una encíclica escrita a sus 81 años, resultado de convicciones, reflexiones y experiencias acumuladas a lo largo de la ya larga vida de un hombre impregnando de filosofía franciscana que había llegado al $\mathrm{Pa}$ pado hacía trece años. En esta encíclica, considerada un documento base para la gestación del catolicismo social, se propugnaría el atajar los problemas inherentes a la cuestión social a través de posiciones ciertamente prointervencionistas, haciendo uso de herramientas de tipo corporativista que recreaban míticamente el desaparecido orden gremial, optando por un intervencionismo moderado si bien la preferencia por la iniciativa personal, familiar y asociativa sobre la estatal marcaba los límites del intervencionismo de acuerdo con el principio de subsidiariedad. En definitiva, la encíclica aportaría una condena firme al liberalismo en cuanto a su responsabilidad sobre el problema obrero y el pauperismo, planteando un nuevo mercado sobre cimientos éticos y basado en preceptos franciscanos por un lado $\mathrm{y}$ neotomistas por otro, reconociendo además el derecho del trabajador al asociacionismo y a la negociación salarial (Pérez Calle, 2015: 988).

3. Un modelo práctico de sociedad $y$ organización económica: la orden tercera franciscana y la empresa social

Como afirman Rivi y Gasparini (2012), desde los inicios del siglo XIX la figura de San Francisco de Asís comenzó a interesar en muchos ambientes tanto intelectuales como artísticos; este renovado interés vendría acompañado por una explosión de expresiones en el campo de la investigación histórica que comparaban los problemas sociales y económicos derivados de la revolución industrial con los que sobrevinieron en la Edad Media cuando las clases burguesas eclosionaron y se expandieron las ciudades.

Ya Pío IX, otro Papa perteneciente a la Orden Tercera, ayudó e incentivó a la misma durante su pontificado (1846-1878). Comenzaron además a utilizar los medios con el fin de difundir y dar visibilidad al modelo terciario. La más antigua publicación de este género son los Annales Franciscaines, iniciada en 1861 por los capuchinos franceses, a la que siguió el periódico L'Année Franciscaine publicado por los Hermanos Menores Recoletos. A partir de ahí, como describe Iriarte (1979), surgirá una larga lista de publicaciones: en 1870 fundaban los capuchinos de Lombardía la revista Annali Francescani y tres años después L'Eco di San Francesco en Nápoles. En España desde 1872 surgieron algunas publicaciones. También en Inglaterra desde 1877, y nuevamente los capuchinos, comenzaron a publicar Franciscan Annals. Lo mismo hicieron en Austria en 1878. Durante el pontificado de León XIII las publicaciones experimentarían un incremento notable: De bode van den H.Franciscus van Assisi (Bélgica, 1880), El Eco Franciscano (España, 1882), Revue Franciscaine (Canada, 1883), St. Franciscus (Holanda, 1884), Dzowonek Trzeciego Zakonu (Polonia, 1885), Oriente Serafico (Italia, 1889), Sendbote des H. Franziskus (Alemania, 1890), Paz y Bien (Chile, 1893), etc.... Todos estos medios venían soportados tanto por religiosos como por laicos, demostrando el interés de la familia religiosa franciscana por la difusión.

Por otra parte, el número de profesos terciarios aumentó notablemente durante el pontificado de León XIII, especialmente a partir de la década de 1890.

\subsection{La estación de los congresos}

En julio de 1893 se reunió en Val-des-Bois la Comisión Internacional de Estudio en la que participaron los representantes de siete provincias franciscanas francesas, belgas y holandesas. Uno de sus objetivos principales fue estudiar lo que había sido la Orden Tercera en tiempos de San Francisco y lo que debía ser en los tiempos contemporáneos, y en este sentido se compararon situaciones inadmisibles, existentes en ambas épocas, como la opresión de los débiles, la división de las clases o el servilismo al lujo y al placer. Definidos los problemas, la hoja de ruta marcaría pasar a la acción a través de los esfuerzos de diversas fraternidades, concluyendo con un mensaje al Papa en el que se definía a la Orden Tercera como "una institución de reforma social cristiana", a lo cual León XIII respondió con gran satisfacción al afirmar sentir cómo ya se estaba ejecutando el mandato que él mismo había confiado a esta Orden y añadiendo sus claros sentimientos de confianza para estos propósitos en la labor de Harmel (Burnod, 1991: 53). A resultas de esta 
reunión se nombrarían los comisarios provinciales franceses para seguimiento de las fraternidades con arreglo a los objetivos marcados y un año después, en julio de 1894 hubo una nueva reunión en Val-des-Bois en la que, entre otros temas relacionados con la acción social, se tomó la determinación de convocar un Congreso para exponer los avances y unificar esfuerzos.

De esta forma, aparte de las experiencias prácticas llevadas a cabo, comenzaría la llamada estación de los congresos terciarios, en los cuales la orden tercera, definiendo como objetivo el campo social, coordinaría esfuerzos de las diversas fraternidades, y llegaría a autodefinirse como institución de reforma social cristiana. De esta forma se celebrarán los congresos más significativos en Francia e Italia en 1894 (Paray-le-Monial) 1895 (Limoges y Asís), 1896 (Reims), 1897 (Nimes), 1900 (Roma). Las resoluciones que perfilaban el modelo de sociedad que debían seguir las fraternidades terciarias en su vida, familias y negocios serían estudiar las reglas de la justicia social, organizar y listar los negocios gestionados cristianamente y formar parte de la vida pública política y social, presentándose a elecciones si existía la posibilidad, además de creer posible la igualdad social a través del equilibrio entre el trabajo y la remuneración. Hubo otros congresos en Suiza, Bélgica, Inglaterra, Alemania y España. Todos los congresos contaron con el apoyo entusiasta del Papa Pecci.

El primero de ellos tuvo lugar en Paray-le Monial entre el 11 y 13 de septiembre de 1894, donde ocupó un cuerpo principal la reflexión sobre la acción social de los terciarios y sus problemas de organización práctica. El congreso tuvo un eje fundamental crítico del capitalismo, y uno de sus productos intelectuales fue un listado de doce resoluciones abiertas al mundo y de corte únicamente social, sin hacer ningún tipo de referencia a la santificación personal. Hay que señalar que la encíclica Auspicato Concessum fue el texto de referencia para todas las reflexiones y conclusiones, releída e interpretada ésta a la luz de la apertura social y el posicionamiento de Rerum Novarum contra los abusos del socialismo y del capitalismo. Toda la información sería remitida al Papa posteriormente, recibiéndola con gran entusiasmo y satisfacción e invitando al Tercer Orden a seguir por ese camino (Mayeur, 1984: 183). De gran relevancia es la carta que León
XIII envía al franciscano Jules de Sacré-Coeur, encargado de fundar a raíz de Val-des-Bois la Comisión de la Orden Tercera para Francia, y que sirvió para aprobar dichas resoluciones, afirmando "Ahora, que Nuestras Encíclicas y exhortaciones hayan podido mucho en vosotros, está clara vuestra obra presente; máximo trabajando con tanto ardor para hacer resurgir el poder natural del Tercer Orden en ayuda a la causa social" (Bigi y Monaco, 1985: 46-47).

La experiencia de Val-des-Bois fue imitada en Italia, convocándose un nuevo congreso en Novara entre 24 y el 27 de septiembre de 1894 con más de ochocientos participantes y en el cual se dirigieron esfuerzos para que los medios diesen la difusión adecuada, logrando de esta forma la asistencia de periodistas. En él fueron aprobados treinta y cinco objetivos, entre los cuales se encontraron los de colaboración en obra social católica como las sociedades de socorro mutuo, las cajas rurales, los sindicatos y las sesiones periódicas de estudio de naturaleza social, aprovechando para definir el Tercer Orden como una institución que "puede y debe concurrir a solucionar la cuestión social, como hacía en otros tiempos", debiendo ser una institución "eminentemente activa y social" (Bigi, 1983: 148).

Rivi y Gasparini (2012) apuntan como ambos congresos despertaron una serie de impresiones acerca de su utilidad en esos momentos, siendo clasificados como complementarios en sus conclusiones, calificando al de Paray-le-Monial con un trasfondo de preocupación por la justicia y al de Novara por la caridad, no matizada ésta última como virtud teologal sino envuelta de un sentido cercano al de solidaridad, ya que viene enlazada con la justicia social. Estas ideas vienen confirmadas en la carta del sacerdote Don Villeneuve al franciscano Jules du Sacré-Coeur, fechada en 10 octubre de 1894 (Bournod: 61) en la que afirma que "Paray quiere la justicia a fin de detener los espantosos desarrollos del proletariado y de la indigencia, fruto de la injusticia social. Novara quiere la caridad a fin de remediar la miseria que golpea a los trabajadores y desempleados involuntarios allí donde no se observa la justicia social".

La referencia anterior a una combinación entre Rerum Novarum y Auspicato Concessum como encíclicas complementarias a la hora de tratar el problema social, se pone de manifiesto en el Congreso de Toulouse de 
1899, en el cual se calificaría a la Auspicato como consecuencia lógica de Rerum Novarum, en el sentido de que los congresos nacen de la propia Auspicato siguiendo la secuencia de regeneración que se dio por inaugurada en $R N$. (Bournod: 63). Ello refuerza la idea de un magisterio de León XIII releído siguiendo más a su lógica que a la cronología, tal y como él mismo invitaría a hacer en Pervenuti all'anno venticinquesimo, su encíclica de 1902 (Del Noce, 2005: 77).

El tercer Congreso francés, celebrado entre el 17 y el 21 de agosto de 1897 en Reims, elevaría tres resoluciones importantes: los terciarios debían estudiar las reglas de la justicia social prestando su voluntariado en obras y asociaciones de las cuales se espera una reorganización social cristiana; debía elaborarse una lista exacta de negocios gestionados cristianamente por oficios y situaciones geográficas, y también se indicaba que, como deber de conciencia, los terciarios debían formar parte de la vida política. (Bournod, 1991: 88).

Al año siguiente, entre el 23 y el 27 de agosto de 1897, tuvo lugar el Congreso de Nimes, en el que se insistiría en el aliento a la iniciativa política sugerido un año antes, como una recomendación de iniciativa individual de cualquier terciario, solo así podía lograrse una influencia efectiva en la organización de la sociedad. Esta visión franciscana que priorizaba la crítica al orden social existente sería comentada en una artículo de 1897 titulado "La rénovation sociale et le Tiers Ordre franciscain" publicado en la revista Le XXème siècle. Puede calificarse este Congreso como la culminación de un movimiento social que se desarrolló de forma continuada desde 1893, con una evolución paralela a la de la democracia cristiana en Francia y que se traducía sobre el plano económico como una crítica viva del capitalismo, la usura y la especulación financiera. (Rivi y Gasparini, 2012: 45).

A la luz de las conclusiones de estos congresos ha de destacarse que, añadido a la versión ya existente de la caridad y a la armonía entre las clases como solución a los males del capitalismo, se pronunció una facción importante dentro de los terciarios franciscanos: aquéllos que creyeron en las ideas democráticas, en la igualdad y justicia social a través del equilibrio entre el trabajo y las remuneraciones, en un mercado ético para los bienes y los trabajadores, y para ello defendieron el auxilio en las ciencias económica y sociológica.

\subsection{Léon Harmel y el modelo de empresa social}

Ya nos hemos referido anteriormente a Léon Harmel (1829-1915), uno de los principales artífices de los congresos. Harmel era un empresario textil francés, terciario franciscano desde 1861 y considerado como "icono del catolicismo social en Francia" (Sierra, 1990: 4). Desde 1854 había organizado una empresa de hilado heredada de su padre en Val-des-Bois según un modelo cristiano de gestión cooperativa basado en la mejora de las condiciones laborales y el empoderamiento de los trabajadores, con el objetivo de demostrar que el acuerdo y el respeto mutuos eran posibles a través del trabajo y la gestión. De esta forma, Harmel convirtió la hilandería de su propiedad en una corporación cristiana. Su motor e ideal fue "vivir en medio de los trabajadores, trabajar con los trabajadores, cuidando de sus necesidades y preocupándose de sus familias" (Paolillo, 1982: 83). Sus objetivos eran favorecer la unión obrera a la vez que despertar el sentido de responsabilidad.

A partir del extenso trabajo de Coffey (2003) sobre Léon Harmel, se concluye claramente cómo para este empresario la sociedad ideal no podía ser otra que la constituida por el modelo de la Orden Tercera, ciudadanos con un modo de comportamiento según instituyó Francisco en el siglo XIII. La sociedad debería comportarse según su modelo en costumbres, tratamiento de la fe y caridad mutua (forma de entender y expresar para Harmel la solidaridad). Ello revelaría además una vuelta al espíritu per se de acción social terciaria y respuestas a la pobreza en forma de soluciones prácticas. Según esta filosofía, en 1879 publicó su Manuel d'une corporation chrétienne donde afirmaba que el haber entrado en la Orden Tercera fue el estímulo fundamental para acometer la reforma cristiana de su modelo empresarial. Éste se sostenía sobre la base del salario justo. Este salario justo, decidido por consenso en un comité de empresa era la variable principal sobre la cual habrían de tomarse las decisiones sobre producción y precios. A partir de ahí, la empresa cristiana no estaba dedicada a la producción, pues en sus instalaciones de Val-des-Bois configuró una aldea operaria, en la que las familias trabajadoras podía residir voluntariamente. En la misma, se constituyó asimismo una organización cooperativa y de corte democrático que se ocupaba de la 
asistencia religiosa, intelectual y material, se instituyó una caja de prestaciones familiares, una caja de mutua asistencial y un centro de estudios sociales.

Totalmente volcado en su empresa y su obra social configurado como un proyecto único de vida, Harmel se dedicó también a organizar peregrinaciones de trabajadores franceses a Roma y a difundir los principios sociales de Rerum Novarum, siendo uno de los principales artífices de las sesiones en Val-des-Bois y de los congresos de la Orden Tercera. La práctica de su negocio asentado en el mercado ético llamaría la atención del Papa León XIII con quien le unió una notoria amistad que les acompañaría durante muchísimos años, y sentó las bases para el modelo de empresa social que tomó Pecci.

$\mathrm{Su}$ mensaje en el Congreso de Reims de 1894 (Paolillo, 1982: 97) muestra claramente la visión de Harmel sobre el papel de la Orden Tercera en la cuestión social, la cual había de ponerse al servicio de los más pobres, inspirada en el espíritu de Francisco, y no solo para aliviar sus necesidades sino para evitar que la desigualdad les llevase a esa necesidad de alivio, trabajando junto a ellos para luchar contra cualquier forma de opresión que diese lugar al pauperismo. En ese empeño, los terciarios debían cumplir con la obligación de fundar instituciones con el fin de organizar el trabajo con igualdad y justicia bajo criterios cristianos o bien ayudar en ellas, siendo las fraternidades franciscanas el mejor medio para llevar a cabo este tipo de proyectos, que en definitiva habrían de responsabilizarse de salvaguardar en el mercado de trabajo el sentimiento cristiano fraterno junto al reino de la justicia social. Así, los terciarios, viviendo en el mundo, habían de sentir como misión la de embarcarse en hacer prevalecer en la sociedad los principios cristianos y la influencia social de la Iglesia.

\section{Conclusiones}

A lo largo de este trabajo hemos intentado dejar de manifiesto cómo el sustrato francis- cano fue fundamental a la hora de configurar un ambiente y un pensamiento económico que pretendía ofrecer soluciones teóricas y prácticas al pauperismo existente, consecuencia de la revolución industrial. El pauperismo no era sino un resultado de la propia problemática relativa a la cuestión social, y la encomienda de búsqueda de estas soluciones fue el principal cometido a abordar por parte de la Orden Tercera de San Francisco, especialmente bajo el pontificado de León XIII, la cual además experimentó un fuerte incremento en número de personas y actividades.

Las soluciones prácticas no solo fueron propuestas sino que existieron modelos reales puntuales, cuyo caso más significativo fue la empresa social del terciario Léon Harmel en Val-des-Bois, una de las figuras más relevantes entre estos franciscanos laicos. El entramado franciscano reforzó su teoría y experiencia dirigiendo grandes esfuerzos hacia la difusión y el propagandismo de esa nueva versión de la caridad y sobre todo de la caridad mutua, concepto que sale de la virtud teologal avanzando hacia matices solidarios y que había de ir acompañado de justicia social y democracia, lo que se lograría a través del trabajo periodístico y de los congresos.

Es de rigor admitir estas raíces y reconocer el papel fundamental del sustrato franciscano así como el trabajo de equipo con la familia franciscana, especialmente con los laicos de la Orden Tercera, en la trayectoria del Papa León XIII, identificado como el gran artífice de la Doctrina Social de la Iglesia. A través de ese trabajo de aliento y equipo, de propuestas, experiencias reales, comunicación y difusión, figuras laicas pertenecientes a la Orden Tercera como Léon Harmel o Giuseppe Toniolo nunca habrían visto la difusión de sus proyectos tal y como acabaron resultando, y posiblemente el Vaticano nunca se habría pronunciado sobre la cuestión social de la forma que finalmente conocemos, ni tampoco se hubiera producido esa invitación a la justicia social y ciertas formas de democracia que llevó a la evolución del catolicismo social hacia los primeros modelos de democracia cristiana. 


\section{Bibliografía}

Bigi, Mariano. 1983. Una proposta una risposta. Vita Francescana. 35, 132-139.

- y Monaco, Luigi. 1985. Magistero dei Papi e fraternitá secolare. Da Pio IX a Giovanni Paolo II. Roma: Testi e studi ad uso dei membri dell'OFS.

Burnod, Jean-Marie. 1991. Le mouvement social franciscain en France. A la suite de Rerum Novarum (1893-1901). París, Les Editions Franciscaines.

Coffey, Joan L. 2003. Léon Harmel: Entrepreneur as Catholic Social Reformer. Indiana, University of Notre Dame Press.

Del Noce, Augusto. 2010. Pensiero della Chiesa e filosofía contemporanea. Leone XIII, Paolo VI, Giovanni Paolo II. En Introvigne, Massimo. La dottrina sociale di Leone XIII. Verona, Fede e cultura, 12

Della Balda, Gabriele. 2010. Leone XIII. Il papa, guardia inflessibile del passato, che ha accennato l'avvenire al mondo. Documenti scelti del pontificato (1878-1903). Perugia, Graphe.it

Eissrich, Daniel. 2017. An Economist's View of the Work of Wilhelm Emmanuel von Ketteler and its influence on the Encyclical Rerum Novarum. En Backhaus, Jürgen; Chaloupeck, Günther y Frambach, Hans A. On the Economic Significance of the Catholic Social Doctrine: 125 Years of Rerum Novarum,Berlin, Springer: 11-25.

Fraile, Pedro. 1998. La retórica contra la competencia en España (1875-1975). Madrid, Fundación Argentaria.

Introvigne, Massimo. 2010. La dottrina sociale di Leone XIII. Verona, Fede e cultura.

Iriarte, Lázaro. 1979. Historia franciscana. Valencia, Ediciones Asís.

Ketteler, Wilhelm Emmanuel, 1864. Die Arbeiterfrage und das Christentum. Franz Kirchheim Editor.

León XIII. 1891. Rerum Novarum. Disponible en http://w2.vatican.va/content/leo-xiii/es/encyclicals/documents/hf_1-xiii_enc_15051891_rerum-novarum.html. Consultado el 02.11.2017.

—. 1879. Aeterni Patris. Disponible en http://w2.vatican.va/content/leo-xiii/es/encyclicals/documents/ hf_1-xiii_enc_04081879_aeterni-patris.html. Consultado el 02.11.2017.

—. 1882. Auspicato Concessum. Disponible en http://w2.vatican.va/content/leo-xiii/en/encyclicals/documents/hf_1-xiii_enc_17091882_auspicato-concessum.html. Consultado el 02.11.2017.

—. 1883. Misericors dei filius. Disponible en https://w2.vatican.va/content/leo-xiii/it/apost_constitutions/ documents/hf_1-xiii_apc_18830530_misericors-dei-filius.html. Consultado el 02.11.2017.

Lombardi, Teodosio. 1980. Storia del francescanesimo. Padova: Edizioni Messaggero.

Malgeri, Francesco. 2000. Leone III. En Enciclopedia dei Papi, 3 vol. Roma, Istituto della enciclopedia italiana, 575-593.

Mayeur, Jean-Marie. 1984. Triers Ordre franciscaine et catholicisme social en France à la fin du XIX siècle. En Vauchez, Andrè (ed.), Mouvements franciscains et société française: XII-XIX siècles. París, Bauchesnes, 181-194.

Montero, Feliciano. 1983. El primer catolicismo social y la Rerum Novarum en España (1889-1902). Madrid, CSIC.

O’Neill, Charles y Domínguez, Joaquín María. 2001. Taparelli d'Azeglio, Luigi. En Diccionario Histórico de la Compañía de Jesús, Vol. II. Madrid, Universidad Pontificia de Comillas, pp. 1.182-1.187.

Orden Franciscana Seglar. 2001 [1978]. Regla, Constituciones Generales y Ritual de la Orden Franciscana Seglar. Madrid, Consejo Nacional de la OFS en España.

Paolillo, Antonio. 1982. Uomini sulle orme di Franceso d'Assisi. Roma, OFS.

Péano, Pierre. 1969. Storia del Terz'Ordine francescano. Módena, Eedizione T.O.F.

Pérez, Begoña. 2015. Catolicismo Social: su influencia en la ciencia y el pensamiento económicos españoles. Opción, Año 31, Especial 3, 984-1.007.

Repiso, Rafael; Ahedo, Josu y Montero, Julio. 2018. The presence of the encyclicals in Web of Science: a bibliometric approach. Scientometrics, 1-14. https://doi.org/10.1007/s11192-017-2636-z

Rivi, Prospero y Gasparini, Andrea. 2012. L'Impegno sociale del Terz'Ordine Francescano. Asís, Edizioni Porziuncula.

Ruiz, Virgilio. 1986. Ética y Mundo Actual. México, D.F, Universidad Iberoamericana, Departamento de Filosofía.

Sierra, José. 1990. El obrero soñado: Ensayo sobre el paternalismo industrial (Asturias, 1860-1917). Madrid, Siglo veintiuno de España Editores. 
Tiano, André. 1993. Alban de Villeneuve-Bargemont (1784-1850): le précurseur de l'état social, ou, un grand notable bien ordinaire. Nimes, Editions Lacour-Ollé

Trincado, Estrella y Perdices, Luis. 2015. Nuevos Investigadores e Investigaciones en la Historia del Pensamiento Económico. Iberian Journal of the History of Economic Thought, Vol 2, Núm. 2, 1-2. 